\title{
Pre-exposure prophylaxis with immune serum globulin for prevention of viral hepatitis in army recruits
}

\author{
JEREMY D KARK* \\ From Medical Corps, Israel Defence Forces, Israel
}

SUMMARY A controlled trial with pre-exposure immune serum globulin was undertaken in Israel Defence Forces (IDF) recruits, an indigenous population living in a hyperendemic area for hepatitis A. The objective was to examine whether the prevailing IDF policy of postexposure administration of immune serum globulin prophylaxis should be modified to further reduce the incidence of infectious hepatitis in the IDF. Altogether 23447 recruits were systematically allocated on their first day of service into an intervention group and a control group. Over the 18-month follow-up period 18 cases of non-B viral hepatitis were identified among the 10943 vaccinees and 41 among the 12504 non-immunised group. Protection over six months was about $85 \%$, and over the entire 18 months 50\%. Protection was evident until about 40 weeks' follow-up and may have persisted for longer. Rates in the non-immunised were lower than expected, alluding to the possibility of herd immunity. IDF immunisation policy was successfully altered after this trial.

Type A viral hepatitis is endemic in the Israel Defence Forces (IDF). Hepatitis B infections, however, account for about $5-10 \%$ of all cases of hepatitis. During the two decades before 1970 large-scale epidemics occurred every three to four years. During such epidemics, the annual incidence of hepatitis in the IDF exceeded 10 per 1000 and reached as high as 15 per thousand.

The last such outbreak took place in 1969. Between 1970 and 1977 the incidence of disease varied from 2.0 to 3.5 per thousand (fig 1). The change in disease pattern coincided with the introduction in 1969 of an improved system of epidemiological surveillance and with an aggressive and wide-scale policy of postexposure prophylaxis with immune serum globulin. ${ }^{1}$ This took the form of immunising whole units after the detection of one or more cases, depending on the character of the unit and the occupation of the patient. This postexposure prophylaxis has proved highly effective in preventing epidemic outbreaks of hepatitis in the IDF. Disease patterns have altered appreciably since 1969 (fig 1).

Nevertheless, infectious hepatitis remained a sufficiently important problem to warrant examination of policy in the IDF. Pre-exposure prophylaxis is commonly recommended for people or

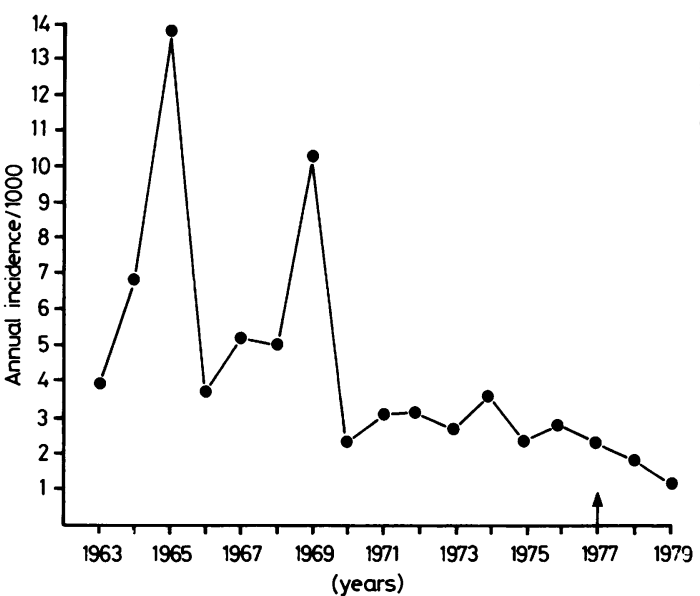

Fig 1 Yearly incidence of viral hepatitis in Israel Defence Forces (per 1000 servicemen in regular service) from 1963 to 1979. (Arrow in 1977 indicates inception of pre-exposure intervention.)

populations moving from areas of low endemicity to hyperendemic areas such as the Middle-East, ${ }^{23}$ and has been tested and used broadly-for example, by the United States armed forces stationed in South

-Present address: Department of Social Medicine, Hebrew University Hadassah School of Public Health and Community Medicine, Faculty of Medicine, Ein Karem, Jerusalem, Israel. 
East Asia ${ }^{4}$ and in Swedish UN soldiers serving in the Middle East. ${ }^{5}$ Nevertheless, the value of pre-exposure immune serum globulin administered to an indigenous population living in a hyperendemic area is a different issue and would depend largely on the extent of the susceptible population-that is, those without prior antibodies to hepatitis A virus.

The aim of this study was to examine whether pre-exposure prophylaxis with immune serum globulin, administered within the framework of a controlled field trial to identified high risk populations in the IDF, would provide an effective preventive measure. Specifically, the objectives were to measure the degree of protection afforded to those immunised, the duration of protection, and the feasibility of using widespread pre-exposure, rather than postexposure, immunisation in high-risk populations in the IDF.

Two high-risk groups, new recruits and regular field units in whom the incidence of infectious hepatitis is substantially higher than the rest of the army population, were selected for intervention. This paper reports the results of observations on 23447 recruits over a follow-up period of 18 months. A separate report describes trial results in 15000 study subjects in field units in which the study design differed. ${ }^{6}$ Altogether over 38000 individuals participated in the two trials.

\section{Methods}

CHARACTERISTICS OF THE STUDY POPULATION The study population consisted of 23447 consecutive male and female recruits who entered the army during part of 1977 . Military service is obligatory in Israel for Jewish (and Druze) men and Jewish women at the age of 18 . Induction of men at this age is almost complete. A small proportion is exempt, mainly because of health limitations. Induction of women is more selective. Thus the male population participating in the trial well represents the broad ethnic and social class diversity of Israeli Jews, while some strata of women are less represented.

Antibodies to hepatitis A virus were quantified in a systematic sample drawn from recruits inducted into the IDF in 1977.7 The prevalence of hepatitis A virus antibody was differentially distributed between the ethnic groups, being considerably higher in both men and women of Eastern origin $(84.4 \%$ and $79.9 \%$ respectively) than in those of Western origin (39.7\% and $30.3 \%$ respectively). The difference between the sexes was not significant when the confounding effects of education were controlled. A significant inverse association was noted between educational level and the prevalence of positive hepatitis A virus antibody. Thus it is apparent that as a major proportion of "Easterners" have had prior exposure to hepatitis A virus, the potential benefit from pre-exposure prophylaxis in this origin group would be limited while that in the Western origin group should be more evident. An estimated $35-40 \%$ of the study population were at risk of contracting hepatitis A virus infections at onset of the trial. Actual proportions of men to women and Easterners to Westerners cannot be presented.

\section{ALLOCATION}

The 23447 recruits were allocated into an intervention and a control group on the basis of the last digit of their identification number (even numbers entering the intervention group and odd numbers the control group). This may be regarded as random allocation (table 1). The even numbers were injected with immune serum globulin on the day of induction into the IDF.

IMMUNE SERUM GLOBULIN (gammaglobulin)

The immune serum globulin used in this trial was regular commercial material purchased from the Cutter Company, USA. Hepatitis A virus antibodies in the lots of immune serum globulin were not measured. The dosage used was a uniform $5 \mathrm{ml}$ injected intramuscularly.

\section{CASE DETECTION AND FOLLOW-UP}

The new recruits were followed up over 18 months. All cases of detected icteric hepatitis in the IDF are routinely sent to civilian hospitals. Reporting is rapid and is assumed to be $100 \%$ complete. Each reported case is routinely investigated by IDF Medical Corps public health personnel, the diagnosis of infectious hepatitis clinically corroborated, hepatitis B surface antigen tested, ISG immunisation status determined, and details as to the circumstances of the infection

Table 1 Classification of study population of new military recruits according to intended and achieved immunisation status with pre-exposure immune serum globulin

\begin{tabular}{|c|c|c|c|c|c|c|}
\hline \multirow{3}{*}{ Target } & \multicolumn{6}{|c|}{ Achieved } \\
\hline & \multicolumn{2}{|l|}{$I S G$} & \multicolumn{2}{|c|}{ Not ISG } & \multicolumn{2}{|l|}{ Total } \\
\hline & No & $\%$ & No & $\%$ & No & $\%$ \\
\hline $\begin{array}{l}\text { ISG } \\
\text { No ISG } \\
\text { Total }\end{array}$ & $\begin{array}{l}10943 \\
- \\
10943\end{array}$ & $\begin{array}{l}93 \cdot 3 \\
\overline{46 \cdot 7}\end{array}$ & $\begin{array}{r}781 \\
11723 \\
12504\end{array}$ & $\begin{array}{r}6 \cdot 7 \\
100 \cdot 0 \\
53 \cdot 3\end{array}$ & $\begin{array}{ll}11 & 724 \\
11 & 723 \\
23 & 447\end{array}$ & $\begin{array}{l}100 \cdot 0 \\
100 \cdot 0 \\
100 \cdot 0\end{array}$ \\
\hline
\end{tabular}


and the possibility of transmission of virus by the case are obtained. Methods for hepatitis B surface antigen testing were not standardised among the different hospitals.

Cases among recruits in whom the first reported symptoms of disease occurred fewer than 10 days after induction were excluded from analysis. Cases that were hepatitis B surface antigen positive were also excluded.

When any study subject developed hepatitis, a decision to administer immune serum globulin - that is, postexposure prophylaxis-to non-immunised personnel in the same unit was taken, based on the same criteria governing the postexposure prophylactic administration of immune serum globulin in the IDF over the past years.

Statistical testing for the difference in occurrence of viral hepatitis in the recruits allocated to the intervention and control groups was by the log rank method. ${ }^{8}$ Withdrawals - that is, early release from service-were considered to have occurred equally in both groups and were not entered into the calculations. Thus the rates computed slightly underestimate the true values. When the condition is rare and withdrawals are not entered into the calculations the log rank test will give results almost identical to the ordinary Chi-square test. Significance testing was performed in two ways: (1) comparing those actually immunised with those not immunised; and (2) considering the initial allocation of subjects, irrespective of whether they were actually immunised or not.

\section{Results}

Among the 23477 new recruits, $93.3 \%$ of the target population of 11724 individuals with even numbers were immunised (table 1).

During the 18-month follow-up in the inductee population 62 cases were reported. Three cases were excluded: two who were hepatitis B surface antigen positive (one case in the immunised group and one in the non-immunised) and the third who developed symptoms within five days of induction (in the immunised group). Therefore 59 cases remained for analysis. In one the immunisation status was not clear. As the subject had been allocated initially to the immunisation group on the basis of his personal army number, it was decided not to change his classification, although most probably he had not been immunised. Over the 18 months 41 cases occurred among the 12504 non-immunised and 18 among the 10943 subjects that received immune serum globulin. The cumulative frequency is described in fig 2.

The difference in incidence between the intervention and the control groups is clear from the onset and although the slopes of the two frequency curves differ appreciably over time, the rate difference is always evident (fig 2 , table 2). At six months the rate is 0.18 per 1000 in the immunised as contrasted with 1.04 per 1000 in the non-immunised. The rate ratio is 5.8 and the percentage protection is $83 \%$. (One of the two cases in the immunised subjects

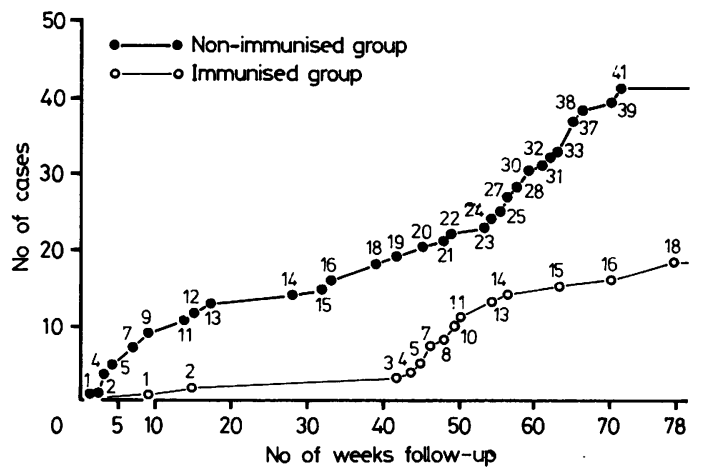

Fig 2 Cumulative frequency of non-B viral hepatitis in immunised and non-immunised new recruits over 18 months.

Table 2 Incidence of non-B viral hepatitis in study populations of new Israel Defence Forces military recruits over 18-month follow-up according to immunisation status in the pre-exposure immune serum globulin trial

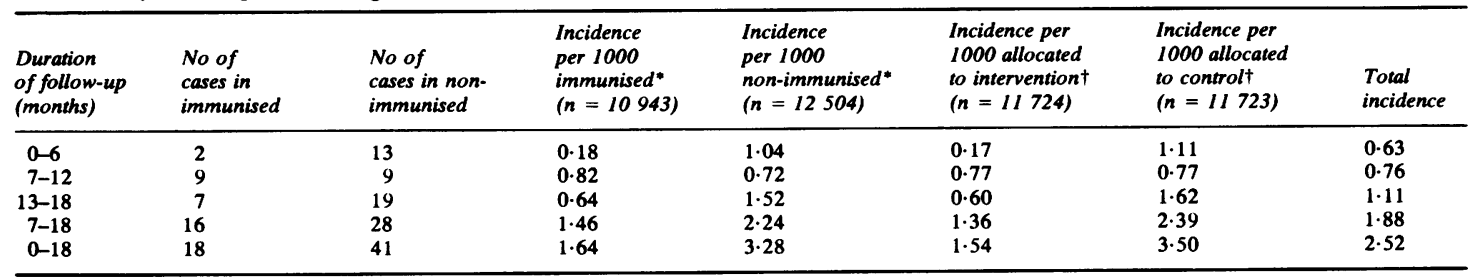

-Incidence calculated according to actual achieved immunisation status.

tIncidence calculated according to prior allocation of subjects into immunised and non-immunised groups. No cases appeared among the 781 identified non-immunised subjects in the intervention group. Therefore the numerators are equal in both calculations and the differences between the two calculations are due to the slightly different denominators. 
is that described above in whom the immunisation status was uncertain.) Until about 40 weeks after intervention the immunised group appears to enjoy an increasing advantage. At this point, however, the slope of the control group increases sharply and begins to converge on the intervention group. At roughly one year after entry into the trial, the curves again diverge. Between seven and 12 months the incidence rates are almost identical-0.82 per 1000 in the immunised and 0.72 in the non-immunised. Between 13 and 18 months the rates are, somewhat surprisingly, 0.64 per 1000 and 1.52 per 1000 respectively ( $58 \%$ protection). Over the seven to 18 month period the rates are 1.46 and 2.24 per thousand respectively ( $35 \%$ protection), and over the entire 18 months 1.64 per thousand in the immunised and 3.28 in the non-immunised (50\% protection). The protection afforded by the vaccine in both sexes was similar (data not shown). The results as presented are somewhat conservative because the numerator in the intervention group includes one case whose immunisation status was doubtful, but the denominator excludes 781 subjects who were allocated to the intervention group but were not immunised. In table 2 the incidence rates are calculated also when the initial allocation of study subjects to the intervention and control groups is maintained. The differences in incidence between the two groups are increased.

Applying the log rank test (table 3), the immunised enjoyed a statistically significant advantage in the first six months $(p=0 \cdot 01)$, the first nine months $(p=0.001)$, and the first 18 months $(p=0.013)$, while in the first 12 months the p value exceeded the 0.05 level. When the comparison is made between the intervention and control groups as originally allocated (table 3), the statistical significance of the differences is enhanced.

When the 18-month follow-up period is subdivided into three consecutive six-month periods, the first six months shows a significant difference between the two groups (see above), seven to 12 months shows no difference, while between 13 and 18 months there are significantly fewer cases among those immunised than in the non-immunised group $(p=0 \cdot 043)$.

The difference in occurrence between the two study groups is maintained over the entire 18 -month study period.

\section{Discussion}

It is apparent that immune serum globulin exerted a strong protective effect over the six-month follow-up period. During the six months, only two cases of "immunisation failure" occurred; of these, one probably did not receive immune serum globulin. The benefit of pre-exposure prophylaxis in this trial in the context of the widespread use of postexposure immune serum globulin in the IDF lay in preventing the first case or cases in an outbreak, because subsequent cases would usually be prevented by postexposure immune serum globulin. Thus the protective efficacy of immune serum globulin in the present trial in preventing type $\mathrm{A}$ hepatitis (or rather, non-B hepatitis) over six months $(83 \%)$ is a conservative estimate because additional cases in the non-immunised subjects were prevented by postexposure prophylaxis applied after the appearance of a case or cases depending on the circumstances and the probability of transmission.

Routine pre-exposure prophylaxis has been used successfully by Swedish UN troops (a very susceptible population) in the Middle East since the $1960 \mathrm{~s}$. In contrast to the indigenous Israeli population of military recruits, only $2 \cdot 4 \%$ of Swedish troops in Cyprus (average age 24.9 years) had antibodies to hepatitis A virus. ${ }^{5}$ Kluge $^{9}$ reported in 1963 that ISG prophylaxis provided $98 \%$ protection of Swedish UN troops in the Gaza strip. In contrast, a very large-scale randomised US Army study in Korea

Table 3 Test of significance (log rank test) for the difference in incidence of non-B viral hepatitis in Israel Defence Forces recruits between the immunised and non-immunised groups classified both according to achieved immunisation status and according to prior allocation to intervention and control groups

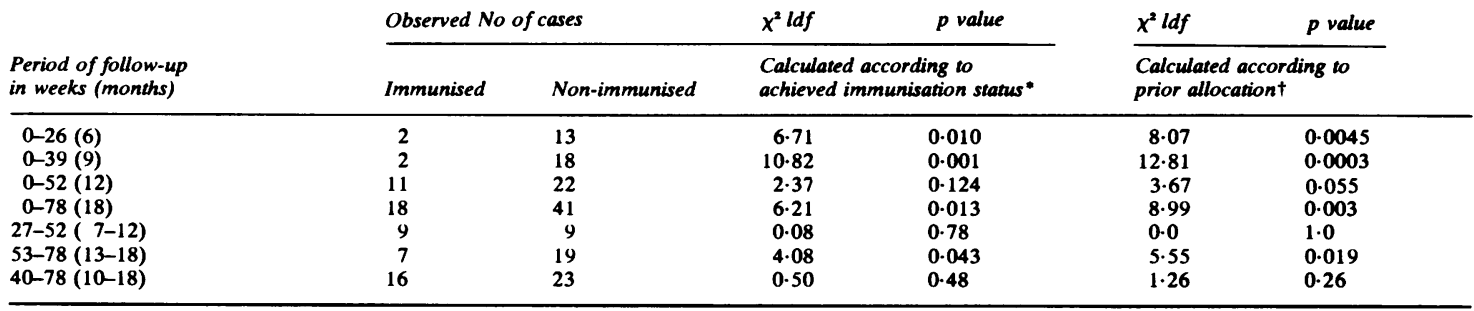

* 10943 immunised and 12504 non-immunised.

$\dagger 11724$ allocated to intervention group and 11723 allocated to control group. 
showed about $50 \%$ protection against icteric hepatitis over six months. ${ }^{4}$ Other studies have also shown protectivity of gammaglobulin produced in one country against hepatitis in other regions ${ }^{10-13}$. In uncontrolled observations United States commercially produced immune serum globulin has appeared to be most successful in preventing large secondary outbreaks in the IDF. Rare failures almost inevitably resulted from immune serum globulin not being administered early enough after exposure.

In the months immediately before inception of the study monthly incidence rates for hepatitis for the entire IDF were high compared with the expectation based on previous years. Continued high ranges were predicted based on the patterns of previous years. Indeed, the expectation was for a hyperendemic year. During the study, however, incidence of disease among the non-immunised dropped well below levels predicted for the season of year. The proportion of total disease in the IDF generated by the non-immunised inductees was very low in comparison with rates in inductees in previous years (data not presented). This reduction in incidence may be unrelated to the intervention. The possibility exists, however, that immunisation of part of the population may affect disease patterns in the non-immunised, and that the unexpectedly low rates seen in the non-immunised inductees is a herd-immunity type effect. A test of this hypothesis would have required an additional totally non-immunised but equally susceptible and equally exposed control group.

One would expect that if herd immunity occurred it would be more apparent during the first six months of follow-up than at 13-18 months when protection by immune serum globulin should have waned. The 13-18 month period is exactly parallel by season to the first six-month period of exposure but is one year later. The incidence in the non-immunised inductees (1.04 per thousand) is somewhat lower than at 13-18 months ( 1.52 per thousand). Although the difference is not statistically significant, the direction of the difference hints at a possible herd-immunity effect. This is supported by the prior knowledge that incidence rates are as a rule substantially higher in the IDF during the first six months of service, which includes basic training, than thereafter. This uncontrolled "evidence," however, is only suggestive.

Regarding duration of protection, the difference in incidence between the non-immunised and immunised increased to 40 weeks of follow-up. It has generally been considered that a pre-exposure dose of $5 \mathrm{ml}$ of immune serum globulin confers protection for up to six months and hence the recommendation of the United States Public Health Service to repeat injections every four to six months. ${ }^{2}$ This does not take into account varying concentrations of antibody to hepatitis $A$ in immune serum globulin. The prolonged protection seen in the present study (40 weeks) is consistent with the experience of Stokes et $a l,{ }^{14}$ who observed protection for five to nine months in institutions for the mentally retarded. Duration of protection may be a function of hepatitis A virus antibody titre of immune serum globulin, and it would appear that even very low residual titres of antibody to hepatitis $A$ are protective, considering that the half-life of IgG is estimated to be a mean of about three weeks.

Between 10 and 12 months of follow-up there was a steeper increase in incidence among the immunised that the non-immunised, indicating loss of protection afforded by immune serum globulin (and possibly even hinting at increased susceptibility in the immunised group, although this could also be a result of chance variation). This possibility relates to the potential problem of immune serum globulin at least theoretically interfering with the immune response in those infected with hepatitis A virus, by neutralising the virus, resulting in lack of passive-active immunity. Thus when the passive protection of immune serum globulin wears off, subjects would remain susceptible to infection. Thus reinfection and disease would simply be delayed until later unless immune serum globulin was repeated periodically. The follow-upo until 18 months does not support this conclusion, but it remains a possibility. There are little published data relating to this issue.

It has been suggested that passive-active immunisation will result only if the hepatitis A virus antibody titre is sufficient to suppress clinical expression of infection, but insufficient to neutralise the virus and prevent seroconversion. ${ }^{15}$ Titres of anti-hepatitis $A$ virus have been shown to differ among lots of immune serum globulin, ${ }^{16}$ and it is thus possible that the mechanism of action of immune serum globulin may vary. ${ }^{17}$ The US Army study in Korea was interpreted by the authors as showing no evidence for passive-active protection. ${ }^{4}$ Studies conducted in institutions for the mentally retarded ${ }^{18} 19$ reported a reduction of icteric hepatitis in those receiving immune serum globulin, but equal occurrence of non-icteric hepatitis among immunised and non-immunised groups, supporting the case for passive-active immunity. Krugman ${ }^{20}$ has shown experimentally that injection of serum containing a mixture of infectious hepatitis $A$ virus and immune serum globulin resulted in no symptomatic hepatitis as compared with a high rate of hepatitis in controls receiving only the infective solution. Two of the eight subjects who received both hepatitis $A$ virus and immune serum globulin seroconverted. Weiland 
et $a l^{5}$ concluded from their study of Swedish UN soldiers in Cyprus that immune serum globulin prophylaxis probably completely prevents seroconversion. One would hope that infection during the period of immune serum globulin protection would result in seroconversion and hence immunity. This issue requires further elucidation.

Somewhat surprisingly, during the last six months of follow-up, from 13 to 18 months, the incidence in those who did not receive immune serum globulin was considerably higher than in the immunised group, indicating the possibility of prolonged protection. No explanation could be found for this peculiar finding. There do not appear to be similar descriptions published. This may well be a chance finding resulting from an arbitrary subdivision into time periods, although these divisions were made before the data were viewed. Over the seven to 18 month period the level of protection was $35 \%$, and over the entire 18-month period the protection was $50 \%$ as contrasted with $83 \%$ over the first six months.

The cost of the intervention in terms of personnel and materials must be contrasted with the outlays due to hospitalisation, service-days lost, and postexposure immunisation. These data cannot be presented; however, a preliminary cost-benefit analysis has indicated that pre-exposure immunisation was economic and provided excellent returns on investment, even when the incidence of disease in the non-immunised study population was unusually low.

Hoofnagle $^{21}$ has recently recommended that pre-exposure prophylaxis of type A hepatitis should probably be used only for travellers to endemic areas and for handlers of newly imported primates. In the context of the IDF, however, we believe that pre-exposure prophylaxis in high-risk populations is an improvement of the previous policy of postexposure immune serum globulin protection, and in addition to reducing endemic morbidity in inductees it reduces the probability of larger localised outbreaks that from time to time are not prevented by postexposure immune serum globulin due to late administration.

After this trial, policy with regard to the use of immune serum globulin in the IDF was modified and routine single immunisation with immune serum globulin instituted for all new inductees during that part of the year when hepatitis morbidity is high. This provides protection during the first months of service that are associated with raised rates. After the concommitant trial in field units, ${ }^{\circ}$ annual pre-exposure prophylaxis was also introduced into this population. Surveillance of the incidence of hepatitis in the IDF over the two years after the policy change proved most encouraging. Incidence rates dropped appreciably in the entire IDF to a low point of 1.25 per thousand in 1979 (fig 1). Immunisation failures in the two intervention populations were exceedingly rare.

As many of the inductees already carry antibody to hepatitis $A$ virus on the day of induction into the army, it is obvious that giving immune serum globulin to all as done in this trial is both unnecessary and wasteful. Identification of hepatitis A virus negative and thus susceptible subjects would be most beneficial. Nevertheless, the techniques presently available to measure hepatitis $A$ antibodies and the infrastructure needed to draw and process blood samples and retrieve the information are too expensive to justify routine screening of all 17-18 year olds before induction. Until a vaccine that induces active immunity against hepatitis $A$ virus is available, it will be necessary to consider strategies for a more selective approach to pre-exposure prevention of viral hepatitis in the IDF.

The help of $Z$ Koufman (in the planning and initiation phases), Nurse $Z$ Alon (supervision of the immunisation), $E$ Witztum and $E$ Nili (verification of case details), and many Israel Defence Forces Medical Corps public health personnel (who routinely interview all patients with hepatitis) is gratefully acknowledged.

\section{References}

${ }^{1}$ Naggan L, Egoz N, Kark J. Role of epidemiologic surveillance in military population in peace-time. International Review of the Army Navy Air Force Medical Service 1975; 48: 189-91.

${ }^{2}$ Public Health Advisory Committee on Immunization Practices. Immune serum globulin for protection against viral hepatitis. Ann Intern Med 1972; 77: 427-30.

${ }^{3}$ Iwarson S, Stenquist K. Tourist hepatitis and gamma globulin prophylaxis. Scand J Infect Dis 1976; 8: 143-4.

${ }^{4}$ A cooperative study. Prophylactic gamma globulin for prevention of endemic hepatitis. Effects of US gamma globulin upon the incidence of viral hepatitis and other infectious diseases in US soldiers abroad. Arch Intern Med 1971; 128: 723-38.

${ }^{5}$ Weiland O, Berg JVR, Back E, Lundbergh P. Immunoglobulin in prophylaxis against hepatitis A among Swedish UN soldiers in an endemic region. Infection 1979; 7: 223-5.

- Kark JD. Pre-exposure prophylaxis of viral hepatitis with immune serum globulin in an endemic area. A trial in field units of the Israel Defence Forces. Scand J Inf Dis (in press).

${ }^{7}$ Kark JD, Bar Shany S. Hepatitis A antibody in Israel Defence Forces recruits. J Med Virol 1980; 6: 341-5.

${ }^{8}$ Peto R, Pike MC, Armitage P, et al. Design and analysis of randomized clinical trials requiring prolonged observation of each patient. II Analysis and examples. Br J Cancer 1977; 35: 1-39. 
${ }^{9}$ Kluge T. Gamma-globulin in the prevention of viral hepatitis: a study on the effect of medium-size doses. Acta Med Scand 1963; 174: 469-77.

${ }^{10} \mathrm{Kluge} T$. Gamma-globulin in the prevention of viral hepatitis, Hoonah, Alaska, 1961. Am J Public Health 1963; 53: 1623-9.

${ }^{11}$ Mosley JW, Reilser DM, Brachott D, Roth D, Weiser J. Comparison of two lots of immune serum globulin for prophylaxis of infectious hepatitis. Am J Epidemiol 1968; 87: 539-50.

${ }^{12}$ Woodson RD, Clinton JJ. Hepatitis prophylaxis abroad: effectiveness of immune serum globulin in protecting peace corps volunteers. JAMA 1969; 209: 1053-8.

${ }^{13}$ Pollock TM, Reid D. Immunoglobulin for the prevention of infectious hepatitis in persons working overseas. Lancet 1969; i: 281-3.

${ }^{14}$ Stokes J, Farquhar JA, Drake ME, Capps RB, Ward CS, Kitts AW. Infectious hepatitis: length of protection by immune serum globulin (gamma globulin) during epidemics. JAMA 1951; 147: 714-9.

${ }^{15}$ Seeff LB, Hoofnagle JH. Immunoprophylaxis of viral hepatitis. Gastroenterology 1979; 77: 161-82.
${ }^{16}$ Froesner GG, Haas H, Hotz G. Hepatitis A antibody in commercial lots of immune serum globulin. Lancet 1977; i: 432-3.

${ }^{17}$ Mosley JW. Epidemiology of HAV infection. In: Vyas $\mathrm{GN}$, Cohen SN, Schmid $\mathrm{R}$, eds. Viral hepatitis. Philadelphia: Franklin University Press, 1978; 85-104.

18 Drake ME, Ming C. Gamma globulin in epidemic hepatitis. Comparative value of two dosage levels, apparently near the minimal effective dose. JAMA 1954; 155: 1302-5.

${ }^{19}$ Krugman S, Ward R, Giles JP, Jacobs AM. Infectious hepatitis. Studies on the effect of gamma globulin and on the incidence of in-apparent infection. JAMA 1960; 174: 823-30.

${ }^{20}$ Krugman S. Effect of human immune serum globulin on infectivity of hepatitis A virus. $J$ Infect Dis 1976; 134: $70-4$.

${ }^{21}$ Hoofnagle JH. Prevention of hepatitis with gamma globulin. Ann Intern Med 1980; 92: 870. 